\title{
Parental care influences leukocyte telomere length with gender specificity in parents and offsprings
}

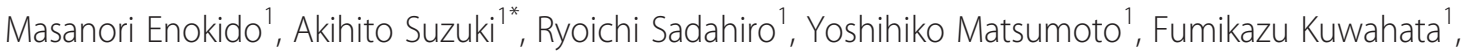 \\ Nana Takahashi ${ }^{1}$, Kaoru Goto ${ }^{2}$ and Koichi Otani ${ }^{1}$
}

\begin{abstract}
Background: There have been several reports suggesting that adverse childhood experiences such as physical maltreatment and long institutionalization influence telomere length. However, there has been no study examining the relationship of telomere length with variations in parental rearing. In the present study, we examined the relationship of leukocyte telomere length with parental rearing in healthy subjects.

Methods: The subjects were 581 unrelated healthy Japanese subjects. Perceived parental rearing was assessed by the Parental Bonding Instrument consisting of the care and protection factors. Leukocyte relative telomere length was determined by a quantitative real-time PCR method for a ratio of telomere/single copy gene.

Results: In the multiple regression analyses, shorter telomere length in males was related to lower scores of paternal care $(\beta=0.139, p<0.05)$, while that in females was related to lower scores of maternal care $(\beta=0.195$, $p<0.01)$.

Conclusion: The present study suggests that there is linear relationship between parental care and telomere length which covers both lower and higher ends of parental care, and that the effects of parental care on telomere length are gender-specific in parents and offsprings.
\end{abstract}

Keywords: Care, Gender specificity, Healthy subjects, Parental rearing, PBI, Telomere length

\section{Background}

Telomeres are repetitive DNA sequences (TTAGGG)n located at the ends of chromosomes and play a crucial role in preventing chromosome fusion and in maintaining genome stability [1,2]. Telomere length is maintained by a cellular enzyme, telomerase, in germ cells and stem cells, while most somatic cells have very low telomerase activity, thus leading to telomere length shortening with cellular division [1,2]. When telomere length reaches a critical point, cellular senescence is triggered, cell division ceases, and the cell dies [1,2]. Thus, telomere length represents a biological marker for cellular aging. Prospective studies have shown that shorter telomere length is a predictor of coronary heart disease [3], cancer [4], progression

\footnotetext{
* Correspondence: suzukiakihito@hotmail.com

'Department of Psychiatry, Yamagata University School of Medicine, 2-2-2 lidanishi, Yamagata 990-9585, Japan

Full list of author information is available at the end of the article
}

of diabetic nephropathy in patients with type 1 diabetes [5], dementia in post-stroke patients [6], and mortality [7]. Shorter telomere length has also been associated with mood disorders, schizophrenia, mild cognitive impairment, and Alzheimer disease [8].

It has been reported that telomere length is influenced by a wide range of factors such as age, gender, race, smoking, physical activity, socioeconomic status, obesity, multivitamin intake, alcohol consumption, and hormone replacement therapy [2], although findings are inconsistent [9]. In relation to psychological factors, shorter leukocyte telomere length is associated with current life stress [10] and personality traits such as pessimism [11] and hostility [12]. Recent studies have focused on the association between telomere length and early-life environment, and these studies have suggested that adverse experiences such as physical abuse and long institutionalization accelerate telomere length shortening $[8,13,14]$, with inconsistent 
findings $[15,16]$. However, there has been few study examining the relationship of telomere length with variations in parental rearing which has a continuum ranging from a positive pole to a negative pole [17].

In attachment theory, Bowlby [18] has proposed that the crucial roles of parents are, first, to provide a secure base and, second, to encourage a child to explore from that base, developing secure attachment in the child. The child with secure attachment grows up to be secure, self-reliant, and co-operative. In contrast, parents who are unresponsive to a child's desire for care and do not allow the child's progressive independence create anxious attachment in the child. Strongly influenced by attachment theory [18], Parker et al. [19] developed the Parental Bonding Instrument (PBI), which assesses perceived rearing attitudes of subject's parents during the first 16 years. The PBI contains the care factor and the protection factor. In the care factor, high scores suggest affection, emotional warmth, and empathy, while low scores indicate emotional coldness, indifference, and neglect. In the protection factor, high scores suggest control, overprotection, and intrusion, while low scores indicate allowance of independence and autonomy. The PBI has been widely used in the field of developmental psychiatry, e.g., studies on the effects of parental rearing on vulnerability factors to depression [20-22]. Meanwhile, low care and high protection assessed by the PBI are shown to be associated with physical diseases such as coronary heart disease [23], gastroesophageal reflux disease [24], Crohn's disease [25], and inflammatory bowel disease [26].

These discussions lead to the hypothesis that telomere length is influenced by variations in parental rearing during childhood in both positive and negative manners. Therefore, we studied the effects of parental rearing assessed by the PBI on leukocyte telomere length in healthy subjects.

\section{Methods}

The subjects were 581 mentally and physically healthy Japanese subjects who were recruited from medical students and hospital staffs living in Yamagata Prefecture. Data collection was performed from September 2003 to October 2011. Absence of a current or past history of psychiatric disorders were confirmed by interviews by well-trained psychiatrists and a questionnaire on psychiatric treatment and diagnosis. Six items selected from the Structured Clinical Interview for DSM-IV Axis I Disorders [27] were used for the psychiatric interview. They were A1 for major depressive episode, A16 for manic episode, B1 for delusions, B6 for hallucinations, E2 for alcohol abuse, and F68 for anxiety disorders. All subjects declared in the check sheet that they had no serious physical diseases. None had his or her parents divorced or deceased before the age of 16. Demographic characteristics of the subjects were shown in Table 1. Three
Table 1 Characteristics of subjects, relative telomere length, and PBI scores

\begin{tabular}{lllll}
\hline & Males & Females & $\boldsymbol{t}$ & $\boldsymbol{p}$ \\
\hline Number of subjects (n) & 340 & 241 & & \\
Age (years, mean \pm SD) & $23.4 \pm 1.6$ & $23.5 \pm 1.9$ & 0.603 & 0.547 \\
$\begin{array}{l}\text { Relative telomere length } \\
\text { (z-score, mean } \pm \text { SD) }\end{array}$ & $-0.1 \pm 1.0$ & $0.1 \pm 1.0$ & 1.615 & 0.107 \\
PBI (score, mean \pm SD) & & & & \\
$\quad$ Paternal care & $23.8 \pm 6.8$ & $25.0 \pm 6.6$ & 2.232 & 0.026 \\
$\quad$ Paternal protection & $10.4 \pm 5.5$ & $10.9 \pm 5.5$ & 1.070 & 0.285 \\
$\quad$ Maternal care & $27.8 \pm 5.2$ & $29.0 \pm 5.8$ & 2.459 & 0.014 \\
$\quad$ Maternal protection & $11.7 \pm 5.9$ & $12.1 \pm 6.1$ & 0.662 & 0.508 \\
\hline PBI; Parental Bonding Instrument, SD; standard deviation. & &
\end{tabular}

hundred forty subjects were males, and 241 were females. The mean \pm SD (range) of age was $23.4 \pm 1.7$ (20-29) years. This study was conducted as part of a series of studies e.g., [20-22,28] on genetic and environmental factors involved in characterization of personality traits in healthy subjects. Two-hundred seven subjects (36\%) out of the present sample overlapped with the subjects of our previous study which examined the relationship between telomere length and personality traits [28]. The study protocol was approved by the Ethics Committee of the Yamagata University School of Medicine. After complete description of the study, written informed consent was obtained from all subjects. The study was conducted according to the principles of the Helsinki Declaration.

The PBI is a self-report scale comprised of 25 items [19]. In the present study, parental rearing was assessed by the Japanese version of the PBI [29], which has been shown to have high reliability, i.e., high internal consistency and stability over time, and high content, concurrent, and construct validity [29].

Genomic DNA was extracted from peripheral leucocytes using a QIAamp DNA Blood Kit (Qiagen, Tokyo, Japan), and was stored at $-80^{\circ} \mathrm{C}$ before PCR amplification. Leukocyte relative telomere length, assessed by a ratio of telomere/single copy gene with the mean data from the triplicate runs, was determined by a quantitative real-time PCR method of Cawthon [30] with the several modifications [28]. Relative telomere length was expressed as a standardized z-score.

Gender differences and inter-correlations in relative telomere length, PBI scores (paternal care, paternal protection, maternal care, and maternal protection), and age were tested by the Student's t-test and the Pearson's linear regression test, respectively. The effects of care and protection scores of parents on relative telomere length were analyzed by the stepwise multiple regression analysis where the dependent variable was relative telomere length, and the independent variables were the PBI scores and age. The analyses were performed in males and females 
separately, because previous studies showed gender specificity in the effects of parental rearing on various psychological factors, i.e., personality traits [20], interpersonal sensitivity [21], and cognitive vulnerability to depression [22]. All statistical analyses were performed by SPSS 14.0 J for Windows (SPSS Japan Inc, Tokyo, Japan), and a p value of less than 0.05 (two-tailed) was regarded as significant.

\section{Results}

The relative telomere length and the PBI scores in males and females are shown in Table 1. Females had higher scores of paternal care $(p=0.026)$ and maternal care $(p=0.014)$ than males (Table 1$)$.

Table 2 shows the correlations among relative telomere length, PBI scores, and age. Tables 3 shows the results of the stepwise multiple regression analyses of relative telomere length with PBI scores and age in males and females. In males, shorter telomere length was related $\left(R^{2}=0.041, p=0.001\right.$, Cohen's $\left.f^{2}=0.043\right)$ to lower scores of paternal care $(p=0.010)$ and higher age $(p=0.005)$, while in females shorter telomere length was related $\left(R^{2}=0.038\right.$, $p=0.002$, Cohen's $\left.f^{2}=0.040\right)$ to lower scores of maternal care $(p=0.002)$ (Table 3 and Figure 1$)$.

\section{Discussion}

In the present study, there were positive correlations between parental care and leukocyte telomere length in both males and females, i.e., the subjects reporting their parents as emotionally cold, indifferent, and neglectful were more likely to have shorter telomere lengths. The present result is in line with the previous studies reporting that severe negative life-events during childhood were associated with shorter telomere length $[8,13,14]$. However, the present study is the first to show the linear relationship between parental care and telomere length which covers both lower and higher ends of parental care. The latter result suggests that higher parental care may have protective effects against telomere shortening in the face of other stressors which may influence telomere length, e.g., financial difficulties, bullying, and physical diseases [8].
The exact mechanism(s) explaining the positive correlation between parental care and telomere length remains unclear, but one possible mechanism may be an involvement of the hypothalamus-pituitary-adrenal (HPA) function. It was reported that mice reared under the condition of low maternal care or maternal separation displayed impaired negative feedback sensitivity to glucocorticoid, and consequently increased adrenocorticotropic hormone and corticosterone response to acute stress [31,32]. In human, subjects with low parental care assessed by the PBI exhibited increased corticotropin-releasing factor in cerebrospinal fluid [33], increased cortisol awaking response [34], and increased cortisol response to stress test [35]. Meanwhile, an in vitro study showed that exposure of human $\mathrm{T}$ lymphocytes to cortisol caused a reduction in telomerase activity [36]. In vivo, elevated urinary nocturnal cortisol levels [37] and increased cortisol response to stress test [38] were associated with shorter telomere length in healthy women. Taken together, it is possible that the relationship between decreased parental care and short telomere length observed in the present study is mediated by impaired HPA function.

Another finding of this study is that the effects of parental care on telomere length were gender-specific, i.e., telomere length in males was correlated with paternal care, while that in females was correlated with maternal care. Our previous studies showed that parental rearing by the same-gender parents had greater impacts on personality traits of harm avoidance and interpersonal sensitivity in healthy subjects $[20,21]$. On the other hands, these personality traits have been reported to be associated with overeating and smoking [39-42] which accelerate telomere shortening [2]. Therefore, the gender-specific effects of parental rearing on telomere length may be mediated by impaired personality development leading to the behaviors accelerating telomere shortening. However, to clarify the biological mechanisms involved in the gender specificity, further study is needed to examine the effects of parental rearing on biological markers including HPA function in males and females separately.

Table 2 Correlations among relative telomere length, PBI scores, and age in males (above diagonal) and females (below diagonal)

\begin{tabular}{|c|c|c|c|c|c|c|}
\hline & 1 & 2 & 3 & 4 & 5 & 6 \\
\hline 1. Relative telomere length & - & $0.136^{*}$ & -0.057 & 0.099 & -0.012 & $-0.149^{* *}$ \\
\hline 2. Paternal care & $0.159^{*}$ & - & $-0.364^{* * *}$ & $0.471^{* * *}$ & $-0.187^{* *}$ & 0.024 \\
\hline 3. Paternal protection & 0.005 & $-0.327^{* * *}$ & - & $-0.175^{* *}$ & $0.459^{* * *}$ & -0.028 \\
\hline 4. Maternal care & $0.195^{* *}$ & $0.440^{* * *}$ & $-0.297^{* * *}$ & - & $-0.379^{* * *}$ & -0.012 \\
\hline 5. Maternal protection & -0.033 & $-0.175^{* *}$ & $0.582^{* * *}$ & $-0.381^{* * *}$ & - & -0.015 \\
\hline 6. Age & -0.121 & -0.055 & 0.101 & -0.077 & -0.002 & - \\
\hline
\end{tabular}

PBI; Parental Bonding Instrument.

Figures on the Table show Pearson's correlation coefficient.

${ }^{*} p<0.05,{ }^{* *} p<0.01,{ }^{* * *} p<0.001$. 
Table 3 Stepwise multiple regression analyses of relative telomere length with PBI scores and age in males and females

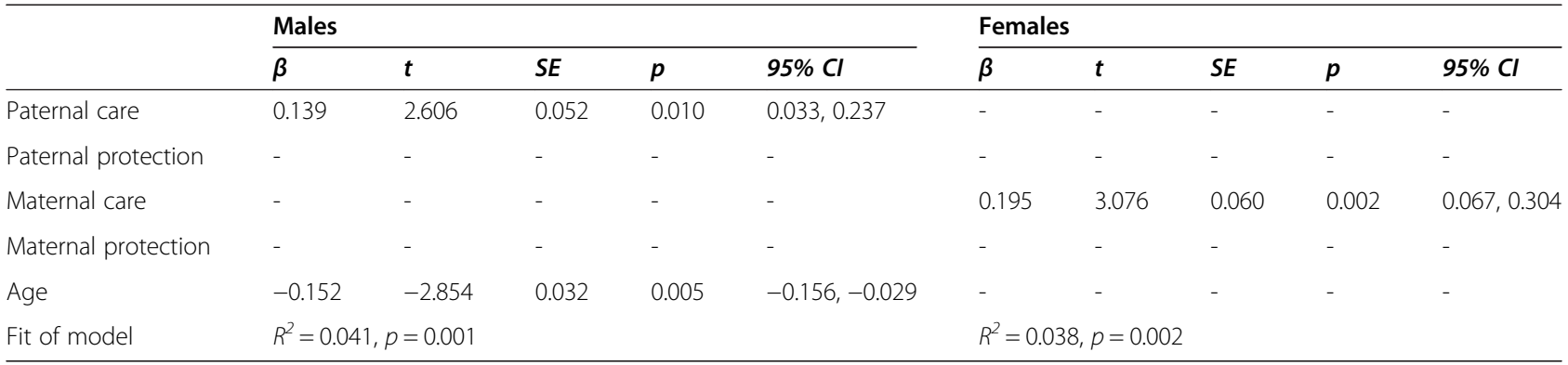

95\% Cl=95\% confidence interval, PBI; Parental Bonding Instrument, SE = standard error, "-"; not significant.

There are several limitations in the present study. Firstly, the present study was a cross-sectional design, i.e., the PBI and telomere length were assessed simultaneously. This raises the possibility that the parental rearing assessed in this study may be biased by perception of subjects. However, Parker [43] showed that the PBI scores provided by their subjects reflected the actual parenting assessed by significant others with acceptable validity. In addition, long-term stability of the PBI scores was shown in a 20-year follow-up study [44]. Therefore, this possibility seems unlikely. On the other hand, a causal relationship between the PBI and telomere length cannot be established in a cross-sectional design, necessitating a longitudinal study. Secondly, the present study did not assess other factors which may influence telomere length, e.g., smoking, excessive alcohol consumption, unhealthy eating, body mass index, childhood maltreatment, socioeconomic status, physical activity [2], and current life stress [10]. In particular, our subjects with low parental care might have received childhood maltreatment from their parents, and this may be driving the association between low parental care and short telomere length. Also, paternal age at birth might have confounded the present results [45], i.e., older father have higher chances of having higher incomes and hence displaying higher care. Therefore, in further studies on the relationship between telomere length and the PBI, the assessment of these factors is needed. Lastly, the subjects of this study were all Japanese, and they were all medical students or hospital staffs, i.e., well-educated people. Although this homogeneity of subjects may be an advantage in genetic association studies, the fact may make it difficult to extrapolate the present results to general populations or other ethnic groups.

\section{Conclusions}

The present study suggests that there is linear relationship between parental care and telomere length which covers both lower and higher ends of parental care, and that the effects of parental care on telomere length are gender-specific in parents and offsprings.
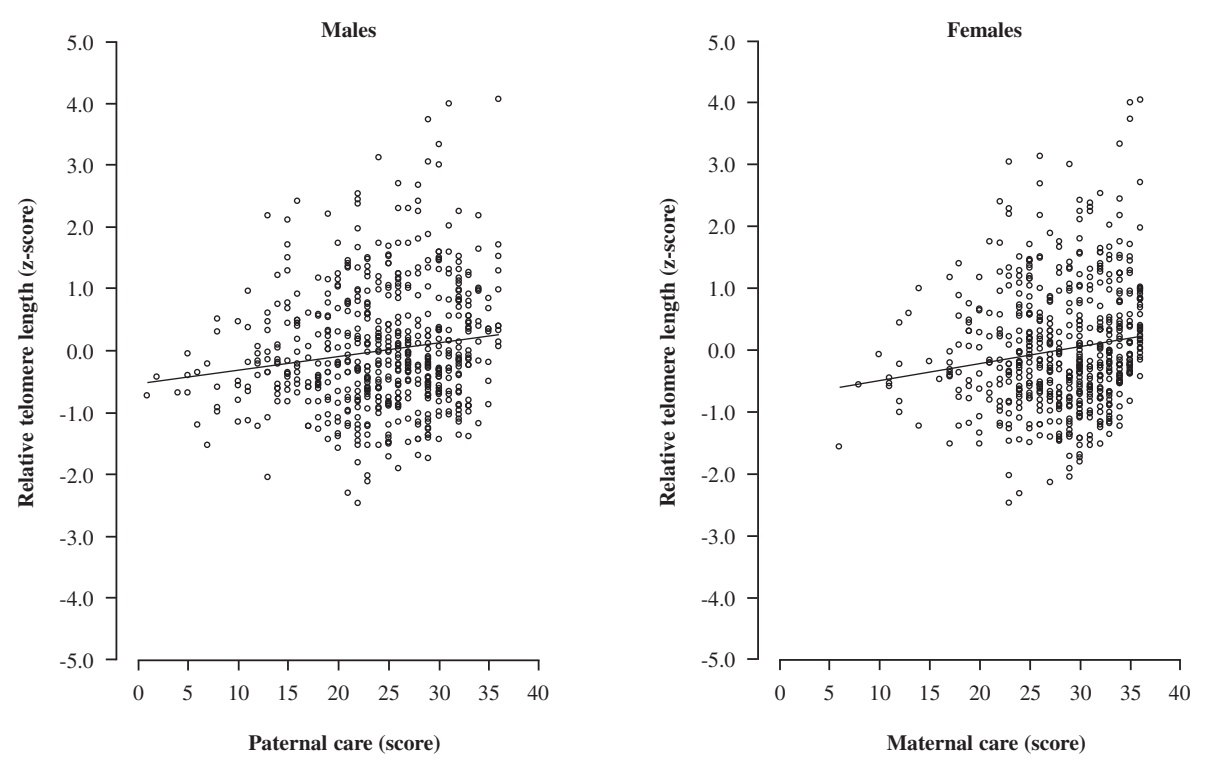

Figure 1 Relationships of relative telomere length with paternal care in males (left) and maternal care in females (right). Telomere length was expressed as a standardized $z$-score. 


\section{Competing interests}

The authors declare that they have no competing interests.

\section{Authors' contributions}

ME elaborated the design of the study with the help of AS and wrote the first draft of the manuscript. RS, YM, FK, and NT were in charge of the data accumulation. $\mathrm{AS}, \mathrm{KG}$ and $\mathrm{KO}$ supervised the entire project and contributed to the editing of the final manuscript. All authors have read and approved the final manuscript.

\section{Acknowledgements}

This study was supported by funding from the Ministry of Education, Culture, Sports, Science and Technology of Japan. This had no effect on this study.

\section{Author details}

${ }^{1}$ Department of Psychiatry, Yamagata University School of Medicine, 2-2-2 lidanishi, Yamagata 990-9585, Japan. ²Department of Anatomy and Cell Biology, Yamagata University School of Medicine, 2-2-2 lidanishi, Yamagata 990-9585, Japan.

Received: 29 June 2014 Accepted: 24 September 2014

Published online: 03 October 2014

\section{References}

1. Blackburn EH: Switching and signaling at the telomere. Cell 2001, 106:661-673.

2. Mather KA, Jorm AF, Parslow RA, Christensen $\mathrm{H}$ : Is telomere length a biomarker of aging? A review. J Gerontol A Biol Sci Med Sci 2011, 66:202-213.

3. Brouilette SW, Moore JS, McMahon AD, Thompson JR, Ford I, Shepherd J, Packard CJ, Samani NJ, West of Scotland Coronary Prevention Study Group: Telomere length, risk of coronary heart disease, and statin treatment in the West of Scotland Primary Prevention Study: a nested case-control study. Lancet 2007, 369:107-114.

4. Ma H, Zhou Z, Wei S, Liu Z, Pooley KA, Dunning AM, Svenson U, Roos G, Hosgood HD III, Shen M, Wei Q: Shortened telomere length is associated with increased risk of cancer: a meta-analysis. PLOS ONE 2011, 6:e20466.

5. Fyhrquist F, Tiitu A, Saijonmaa O, Forsblom C, Groop PH, FinnDiane Study Group: Telomere length and progression of diabetic nephropathy in patients with type 1 diabetes. J Intern Med 2010, 267:278-286.

6. Martin-Ruiz C, Dickinson HO, Keys B, Rowan E, Kenny RA, Von Zglinicki T: Telomere length predicts poststroke mortality, dementia, and cognitive decline. Ann Neurol 2006, 60:174-180.

7. Cawthon RM, Smith KR, O'Brien E, Sivatchenko A, Kerber RA: Association between telomere length in blood and mortality in people aged 60 years or older. Lancet 2003, 361:393-395.

8. Price LH, Kao HT, Burgers DE, Carpenter LL, Tyrka AR: Telomeres and early-life stress: an overview. Biol Psychiatry 2012, 73:15-23.

9. Weischer M, Bojesen SE, Nordestgaard BG: Telomere shortening unrelated to smoking, body weight, physical activity, and alcohol intake: 4,576 general population individuals with repeat measurements 10 years apart. PLoS Genet 2014, 10:e1004191.

10. Epel ES, Blackburn EH, Lin J, Dhabhar FS, Adler NE, Morrow JD, Cawthon RM: Accelerated telomere shortening in response to life stress. Proc Natl Acad Sci U S A 2004, 101:17312-17315.

11. O'Donovan A, Lin J, Dhabhar FS, Wolkowitz O, Tillie JM, Blackburn E, Epel E: Pessimism correlates with leukocyte telomere shortness and elevated interleukin-6 in post-menopausal women. Brain Behav Immun 2009, 23:446-449.

12. Brydon L, Lin J, Butcher L, Hamer M, Erusalimsky JD, Blackburn EH, Steptoe A: Hostility and cellular aging in men from the Whitehall II cohort. Biol Psychiatry 2012, 71:767-773.

13. Drury SS, Theall K, Gleason MM, Smyke AT, De Vivo I, Wong JYY, Fox NA, Zeanah $\mathrm{CH}$, Nelson CA: Telomere length and early severe social deprivation: linking early adversity and cellular aging. Mol Psychiatry 2012, 17:719-727.

14. Shalev I, Moffitt TE, Sugden K, Williams B, Houts RM, Danese A, Mill J, Arseneault $L$, Caspi A: Exposure to violence during childhood is associated with telomere erosion from 5 to 10 years of age: a longitudinal study. Mol Psychiatry 2013, 18:576-581.

15. Jodczyk S, Fergusson DM, Horwood L, Pearson JF, Kennedy MA: No association between mean telomere length and life stress observed in a 30 year birth cohort. PLOS ONE 2014, 9:e97102.
16. Glass D, Parts L, Knowles D, Aviv A, Spector TD: No correlation between childhood maltreatment and telomere length. Biol Psychiatry 2010, 68:e21-e22.

17. Asok A, Bernard K, Roth TL, Rosen JB, Dozier M: Parental responsiveness moderates the association between early-life stress and reduced telomere length. Dev Psychopathol 2013, 25:577-585.

18. Bowlby J: The making and breaking of affectional bonds. I. Aetiology and psychopathology in the light of attachment theory. Br J Psychiatry 1977, 130:201-210.

19. Parker G, Tupling $H$, Brown LB: A parental bonding instrument. $\mathrm{Br} J$ Med Psychol 1979, 52:1-10.

20. Oshino S, Suzuki A, Ishii G, Otani K: Influences of parental rearing on the personality traits of healthy Japanese. Compr Psychiatry 2007, 48:465-469.

21. Otani K, Suzuki A, Shibuya N, Matsumoto Y, Kamata M: Dysfunctional parenting styles increase interpersonal sensitivity in healthy subjects. J Nerv Ment Dis 2009, 197:938-941.

22. Otani K, Suzuki A, Kamata M, Matsumoto Y, Shibuya N, Sadahiro R, Enokido M: Parental overprotection increases sociotropy with gender specificity in parents and recipients. J Affect Disord 2012, 136:824-827.

23. Almeida ND, Loucks EB, Kubzansky L, Pruessner J, Maselko J, Meaney MJ, Buka SL: Quality of parental emotional care and calculated risk for coronary heart disease. Psychosom Med 2010, 72:148-155.

24. Ercolani M, Farinelli M, Trombini E, Bortolotti M: Gastroesophageal reflux disease: attachment style and parental bonding. Perc Mot Skills 2004, 99:211-222.

25. Agostini A, Rizzello F, Ravegnani G, Gionchetti P, Tambasco R, Straforini G, Ercolani M, Campieri M: Adult attachment and early parental experiences in patients with Crohn's disease. Psychosomatics 2010, 51:208-215.

26. Agostini A, Rizzello F, Ravegnani G, Gionchetti P, Tambasco R, Ercolani M, Campieri M: Parental bonding and inflammatory bowel disease. Psychosomatics 2010, 51:14-21.

27. First MB, Spitzer RL, Gibbon M, Williams JBM: Structured Clinical Interview for DSM-IV Axis I disorders - Clinician Version. Washington DC: American Psychiatric Association; 1997.

28. Sadahiro R, Suzuki A, Enokido M, Matsumoto Y, Shibuya N, Kamata M, Goto K, Otani K: Relationship between leukocyte telomere length and personality traits in healthy subjects. Eur Psychiatry 2014, (in press).

29. Ogawa M: A study on reliability and validity of Japanese version of PBI (Parental Bonding Instrument). Seishinkachiryogaku 1981, 6:1193-1201 (Japanese).

30. Cawthon RM: Telomere measurement by quantitative PCR. Nucleic Acids Res 2002, 30:e47.

31. Liu D, Diorio J, Tannenbaum B, Caldji C, Francis D, Freedman A, Sharma S, Pearson D, Plotsky PM, Meaney MJ: Maternal care, hippocampal glucocorticoid receptors, and hypothalamic-pituitary-adrenal responses to stress. Science 1997, 277:1659-1662.

32. Plotsky PM, Thrivikraman KV, Nemeroff CB, Caldji C, Sharma S, Meaney MJ: Long-term consequences of neonatal rearing on central corticotropin-releasing factor systems in adult male rat offspring. Neuropsychopharmacology 2005, 30:2192-2204.

33. Lee RJ, Gollan J, Kasckow J, Geracioti T, Coccaro EF: CSF corticotropin-releasing factor in personality disorder: relationship with self-reported parental care. Neuropsychopharmacology 2006, 31:2289-2295.

34. Engert V, Buss C, Khalili-Mahani N, Wadiwalla M, Dedovic K, Pruessner JC: Investigating the association between early life parental care and stress responsivity in adulthood. Dev Neuropsychol 2010, 35:570-581.

35. Engert V, Efanov SI, Dedovic K, Dagher A, Pruessner JC: Increased cortisol awakening response and afternoon/evening cortisol output in healthy young adults with low early life parental care. Psychopharmacology (Berl) 2011, 214:261-268.

36. Choi J, Fauce SR, Effros RB: Reduced telomerase activity in human T lymphocytes exposed to cortisol. Brain Behav Immun 2008, 22:600-605.

37. Epel ES, Lin J, Wilhelm FH, Wolkowitz OM, Cawthon R, Adler NE, Dolbier C, Mendes WB, Blackburn EH: Cell aging in relation to stress arousal and cardiovascular disease risk factors. Psychoneuroendocrinology 2006, 31:277-287

38. Tomiyama AJ, O'Donovan A, Lin J, Puterman E, Lazaro A, Chan J, Dhabhar FS, Wolkowitz O, Kirchbaum C, Blackburn E, Epel E: Does cellular aging relate to patterns of allostasis? An examination of basal and stress reactive HPA axis activity and telomere length. Pysiol Behav 2012, 106:40-45. 
39. Brook JS, Zhang C, Brook DW, Koppel J, Whiteman M: Psychological predictors of nicotine dependence among women during their mid-sixties. Am J Addict 2012, 21:302-312

40. Hamann DM, Wonderlich-Tierney AL, Vander Wal JS: Interpersonal sensitivity predicts bulimic symptomatology cross-sectionally and longitudinally. Eat Behav 2009, 10:125-127.

41. Peterson CB, Thuras P, Ackard DM, Mitchell JE, Berg K, Sandager N, Wonderlich SA, Pederson MW, Crow SJ: Personality dimensions in bulimia nervosa, binge eating disorder, and obesity. Compr Psychiatry 2010, 51:31-36.

42. Pomerleau CS, Pomerleau OF, Flessland KA, Basson SM: Relationship of tridimensional personality questionnaire scores and smoking variables in female and male smokers. J Subst Abuse 1992, 4:143-154.

43. Parker G: Parental reports of depressives: an investigation of several explanations. J Affect Disord 1981, 3:131-140.

44. Wilhelm K, Niven H, Parker G, Hadzi-Pavlovic D: The stability of the parental bonding instrument over a 20-year period. Psychol Med 2005, 35:387-393.

45. Eisenberg DT, Hayes MG, Kuzawa CW: Delayed paternal age of reproduction in humans is associated with longer telomeres across two generations of descendants. Proc Natl Acad Sci U S A 2012, 109:10251-10256.

doi:10.1186/s12888-014-0277-9

Cite this article as: Enokido et al:: Parental care influences leukocyte telomere length with gender specificity in parents and offsprings. BMC Psychiatry 2014 14:277.

\section{Submit your next manuscript to BioMed Central and take full advantage of:}

- Convenient online submission

- Thorough peer review

- No space constraints or color figure charges

- Immediate publication on acceptance

- Inclusion in PubMed, CAS, Scopus and Google Scholar

- Research which is freely available for redistribution 